\title{
Users’ Assessment of Personal FANS IN A WARM OfFICE SPACE IN BRAZIL
}

M. André , C. Buonocore , L. De Castro*, and R. Lamberts Laboratory for Energy Efficiency in Buildings, Florianopolis, Brazil

\begin{abstract}
The use of personal fans allows improving thermal comfort and energy savings in warm office spaces. This is due to individual adjustment and extended indoor temperature acceptability. However, to achieve that, the usability of fans must be assured. Therefore, an experiment with 40 people of various age groups was carried out to assess four types of fans, one of which is an evaporative cooling device. The goal was to find out which criteria should be used for selecting a fan to implement in an office space. Results show that airflow sensation and speed adjustment are considered the most important, although, noise is also very important, and cost can be an eliminatory criterion. The evaporative device was the best rated even in a space with 70 to $80 \%$ relative humidity, as users considered it to have a smooth controllable airflow. The results highlight these aspects should be considered in the selection of a personal fan and could also drive the industry to improve fans design for increasing usability and expanding the use of these systems.
\end{abstract}

Keywords: Desk Fan; Thermal Comfort; Office; Warm Environment; Personal Conditioning System.

$$
\begin{aligned}
& \text { تقييم المستذدمين للمراوح المكتبية في المكاتب الدافئة في البرازيل } \\
& \text { م. أندريهو كـ بونوكور ول. دي كلسترو و ر لالامبرس }
\end{aligned}
$$

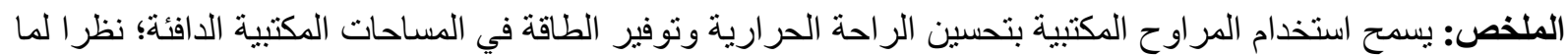

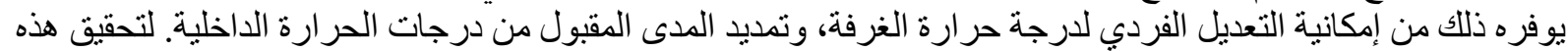

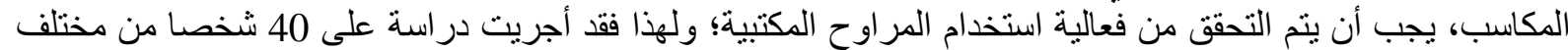

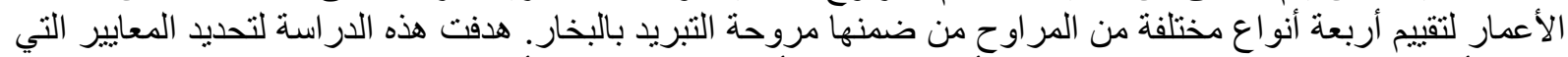

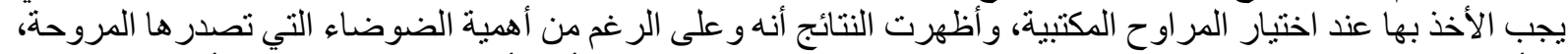

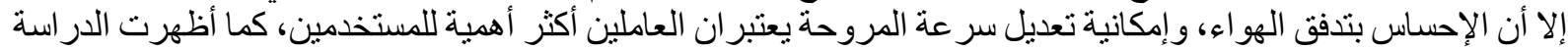

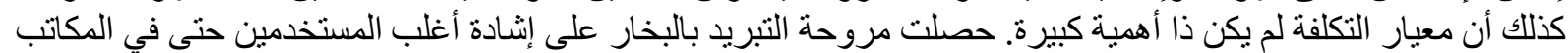

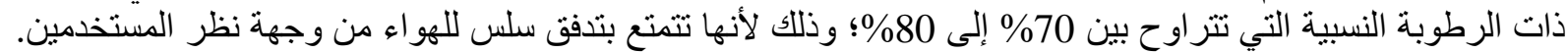

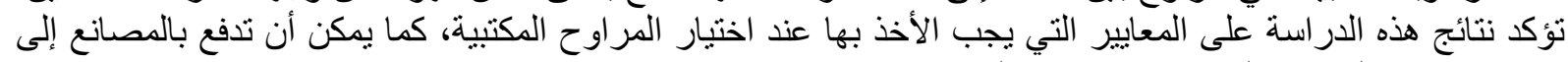
تحسين تصميم المراوح المكتبية، مما يؤدي إلى زئي زيادة استخدامها.

الكلماث المفتاحية: مروحة المكتب؛ الر احة الحرارية؛ مكتب؛ بيئة دافئة؛ نظام التكييف الشخصي. 


\section{INTRODUCTION}

In the face of the prospect of global warming, it is important to rethink the way we condition buildings, so lower energy-consuming strategies are expanded. To do that, conditioning design could change the focus from room to microclimate conditioning by applying stimuli close to the body. Personal conditioning systems (PCS) allow local adjustment of thermal conditions, enabling a group of people in the same space to control their microclimate according to personal demands (Brager, Zhang and Arens, 2015). In addition, local stimuli can generate alliesthesia, which produces overall thermal comfort (De Dear, 2011) with much lower energy consumption than needed for conditioning the total air volume of a room (Xu et al., 2017). This approach allows the extension of cooling setpoint temperature, which could produce up to $70 \%$ energy savings (Hoyt, Arens and Zhang, 2015).

Many types of personal devices have been proposed and studied in the last decade (André, De Vecchi and Lamberts, 2020b). However, desk fans are considered one of the most efficient devices for warm conditions (M. He et al., 2017; Luo et al., 2018; Warthmann et al., 2018). They are also easy to implement for being independent of the cooling system infrastructure (Boerstra, 2010). Previous studies indicate occupants find $30{ }^{\circ} \mathrm{C}$ acceptable when they have desk fans (Mishra, Loomans and Hensen, 2016; Warthmann et al., 2018) since the increment of air movement reduces the warm sensation up to $3{ }^{\circ} \mathrm{C}$ (Zhang, Arens and Zhai, 2015). In shared office spaces, it is common for the occupant to buy the fan when he/she is uncomfortable (Boerstra, 2010), but the energy savings are not perceived by him/her, because the building's consumption is paid by his/her employer (Y. He et al., 2017). Therefore, to achieve the energy savings potential allowed by the extension of setpoint temperature, fans usability and attractiveness are very important to increase occupants' willingness to use them and meet users' needs. Knecht et al. (2016) indicate usability can be influenced by aesthetics, ease of use of controls and the level of adjustability provided by the device. So, design issues can decrease the device usability, hindering its potential to improve users' thermal comfort and energy savings. Some design issues have already been identified in previous studies.

André et al. (2020a) identified users avoided increasing the fan speed because it also increased the noise level, causing an acoustic nuisance. Schiavon et al. (2017) indicate that, in shared office spaces, fan noise might be more annoying to the person who is not using it, as no positive effect is perceived by him/her. Therefore, the multiple domains of comfort must be considered as thermal, visual, acoustic and air quality may influence each other (Schweiker et al., 2020). Another important aspect is fan airspeed adjustment limitation, which may constrain the maximum airspeed and the fine-tuning, as usually, fans have fixed speed levels. In some studies, it was identified that users wanted higher airspeed, but did not increase it to the maximum possible level (Zhai et al., 2013), probably because they preferred an intermediate speed level that could not be set by the device. In warmer environments, users indicated a preference for more airspeed even though the maximum speed level was selected (M. He et al., 2017; Zhai et al., 2017). This indicates that the maximum speed achieved by the fan was not enough, which may have limited the temperature acceptability. To achieve a higher body cooling effect, the stimuli of the device should target the torso and face (Zhang et al., 2010). These are usually affected by desk fans (Schiavon and Melikov, 2009; Simone et al., 2014). However, depending on the fan size and vertical rotation adjustment capability the air jet might hit only the belly and arms (André, De Vecchi and Lamberts, 2020a). Thus, rotation adjustment in the vertical axis is also important to boost the fan effect. On the other hand, fan size has two implications - restriction of the affected surface area and adaptation to a workstation, where the space available is usually limited for each person. Schiavon and Melikov (2009) found that increasing the affected body surface area increases heat loss and fan cooling effect. However, in a shared workspace, an individual table area is limited and occupied by paperwork, computer and other supplies that constrain available space, so smaller devices are usually easier to implement.

As identified in the literature, design aspects can influence desk fans' usability. However, few studies were found comparing devices to address these issues. Therefore, this study aims to identify the criteria users find most important when choosing and using a personal ventilative device. These criteria could be used for proposing guidelines for the industry and designers to improve this type of device. It could also help researchers and users to select devices with better usability.

\section{METHOD}

To assess users' acceptability and willingness to use personal fans in shared office spaces, an experiment was set in the Laboratory for Energy Efficiency in Buildings (LabEEE) of the Federal University of Santa Catarina. The building is in Florianopolis, a city in the southeast of Brazil with a climate classified as subtropical by Köppen-Geiger (Peel, Finlayson and McMahon, 2007) and as 2A by ASHRAE 169 (2020). Ten 2-hour sessions were carried out in February and March 2020, as they are summer months. Four people - working on laptops - were included in each section. The experiment room is $17 \mathrm{~m}^{2}$ with two external masonry walls and lightweight internal partitions (drywall and plywood with acoustic insulation). Windows were shaded externally by fixed shading and internally by blinds, which were controlled by the researchers during the experiment to allow diffused 
daylight and prevent direct solar radiation.

Throughout each experiment session, environmental thermal conditions were measured with data loggers (HOBO UX-100) at three different points, one inside the room, one in the hallway and another in the building corridor. This way, the different thermal conditions participants would be exposed to during the experiment could be registered. Sensors were turned on 30 minutes before the beginning of each session, and they recorded air temperature (from $20^{\circ} \mathrm{C}$ to $70{ }^{\circ} \mathrm{C} \pm$ $0.21^{\circ} \mathrm{C}$ ) and relative humidity (from $15 \%$ to $95 \% \pm$ $3.5 \%)$ every minute.

\section{Experiment procedure}

Each session followed the procedures summarised in Figure 1. The sessions started when participants entered the room, opened the laptops, and filled a Personal Information Questionnaire (InfoQ). Then, participants received instructions about procedures. The experiment was developed so that each occupant could use four personal ventilation devices and could evaluate them comparatively at the end of the experiment. The assessment was done by completing the Fan Assessment Questionnaire (FanQ). Each device had the same period of usage (15 minutes) and their order was drawn randomly before each session.

Participants were allowed to freely activate the device, adjust airspeed and position the fan as they please during each usage period (indicated in grey in Figure 1). An interval was established to create a gap between the use of each device, lowering the influence of one piece of equipment over the next. Continuous use was also avoided as it could reduce the fan cooling effect (Parkinson and De Dear, 2016). To maintain the use demand, the experiment included variations on personal and environmental conditions during these intervals. The personal variation was based on increasing participants' metabolic rate. This was achieved with walks through the building and a food break. The walk break consisted of participants walking a 5-minute path outside the experiment room, passing through the laboratory hallway, crossing the building corridor, going down two flights of stairs down to the lower floor, crossing the corridor again, going up two flights of stairs, passing the lab hallway and returning to the experiment room. Building corridors were always naturally ventilated, while the lab hallway was not controlled by the researchers during the experiment; therefore, it could be either naturally ventilated or air-conditioned, depending on the day. The food break lasted 10 minutes, and participants were led to a naturally ventilated kitchen in front of the experiment room, where sweet foods, coffee and water were offered. Environmental conditions variation was based on changing the conditioning mode. The air conditioning (AC) started completely off, simulating a dead band condition.

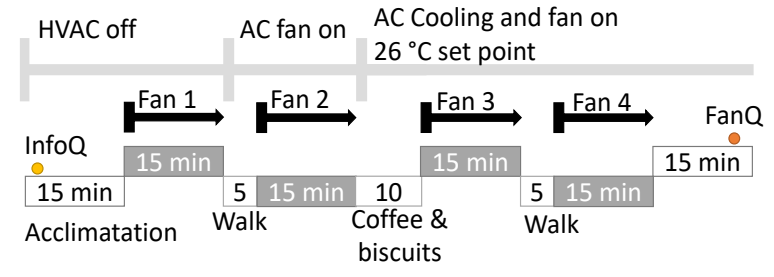

- Personal information questionnaire (InfoQ)

- Fans assessment questionnaire (FanQ)

Figure 1. Experiment procedure.

Table 1. Tested devices specification.

\begin{tabular}{|c|c|c|c|c|c|c|c|c|c|}
\hline $\begin{array}{l}\text { Fan label and the } \\
\text { main characteristic }\end{array}$ & \multicolumn{3}{|c|}{$\begin{array}{l}\text { a) } \\
\text { 3-speed ventilative }\end{array}$} & $\begin{array}{l}\text { b) } \\
\text { 1-speed } \\
\text { ventilative }\end{array}$ & \multicolumn{2}{|c|}{$\begin{array}{l}\text { c) } \\
\text { 2-speed } \\
\text { ventilative }\end{array}$} & \multicolumn{3}{|c|}{$\begin{array}{l}\text { d) } \\
\text { 23-speed evaporative }\end{array}$} \\
\hline \multicolumn{10}{|l|}{ Sales image } \\
\hline $\begin{array}{c}\text { Number of Speed } \\
\text { levels }\end{array}$ & 1 & 2 & 3 & 1 & 1 & 2 & $\begin{array}{c}1 \\
\text { (5 track) }\end{array}$ & 2 (12 track) & $\begin{array}{c}3 \\
(23 \text { track }) \\
\end{array}$ \\
\hline Air speed (m/s) & 1.25 & 2.40 & 2.98 & 1.17 & 1.88 & 2.33 & 0.81 & 1.30 & 1.78 \\
\hline $\begin{array}{l}\text { Sound power level } \\
(\mathrm{dBA})^{\mathrm{a}}\end{array}$ & 43.50 & 48.50 & 51.90 & 42.30 & 43.20 & 44.40 & 39.90 & 48.60 & 53.90 \\
\hline Power $(\mathrm{W})^{\mathrm{b}}$ & \multicolumn{3}{|c|}{4.50} & 3.00 & \multicolumn{2}{|c|}{10.00} & \multicolumn{3}{|c|}{10.00} \\
\hline Cost (USD) ${ }^{\mathrm{C}}$ & \multicolumn{3}{|c|}{$\$ 6.12$} & $\$ 8.45$ & \multicolumn{2}{|c|}{$\$ 11.02$} & \multicolumn{3}{|c|}{$\$ 367.33$} \\
\hline $\begin{array}{c}\text { Dimension } \\
\text { h x w x d (cm) }\end{array}$ & \multicolumn{3}{|c|}{$10 \times 15 \times 5$} & $15 \times 15 \times 12$ & \multicolumn{2}{|c|}{$21 \times 20 \times 15$} & \multicolumn{3}{|c|}{17 x 17 x 17} \\
\hline Colour & \multicolumn{3}{|c|}{ Orange /green /black } & Black & \multicolumn{2}{|c|}{ Blue \& white } & \multicolumn{3}{|c|}{ White or black +7 light colours } \\
\hline $\begin{array}{c}\text { Rotation } \\
\text { adjustment }\end{array}$ & \multicolumn{3}{|c|}{ none } & horizontal & \multicolumn{2}{|c|}{$\begin{array}{c}\text { vertical and } \\
\text { horizontal }\end{array}$} & \multicolumn{3}{|c|}{ none } \\
\hline Other & \multicolumn{3}{|c|}{$\begin{array}{l}\text { works unplugged w/ } \\
\text { rechargeable battery }\end{array}$} & - & \multicolumn{2}{|c|}{$\begin{array}{l}\text { clamp-fixing } \\
\text { option }\end{array}$} & \multicolumn{3}{|c|}{ water tank for evaporative cooling } \\
\hline
\end{tabular}

\footnotetext{
a Measured at $50 \mathrm{~cm}$ distance from the centre of the fan

${ }^{\mathrm{b}}$ Indicated by the supplier

c Currency of 4.0835 BRL to USD on 01/07/2020. Reference: http://www.ipeadata.gov.br/
} 
After the use of the first selected fan - Fan 1 in Figure 1 - during the first break, the AC fan was turned on at airspeed level 2. And during the second break (after Fan 2 usage), the cooling was turned on at the $26^{\circ} \mathrm{C}$ setpoint temperature and the AC fan airspeed was reduced to level 1 . These variations were not communicated to participants so their decisions on whether to turn on the devices were not influenced by their knowledge of system operation, but mainly by their thermal perception and demand. This strategy was intended to mimic an automatic operation where occupants are not aware of the system status. However, HVAC status was informed when requested. It is noteworthy that the room was kept with all windows closed and open blinds before the beginning of the experiment to increase the indoor temperature. Therefore, in the first 15 minutes of the experiment participants would have to acclimate to a warm condition. This first phase also aimed to level participants' initial metabolic rate, so that any activity performed before the beginning of the experiment would be stabilised and would not influence either their thermal perception or demand.

\section{Selected Devices}

During the experiment sessions, each participant received one device at a time from a group of four devices. Therefore, each participant evaluated all four devices shown in Table 1 . The devices were selected based on availability in the local market and their characteristics, to bring more variety to the experiment. Their main differences are different levels of airspeed adjustment; vertical rotation adjustment in just two of them; slightly different sizes; and very different aesthetics. In addition, option $d$ is an evaporative cooling fan, which recirculates air through an internal filter soaked in water. This option has also a much higher purchase cost than the other ones.

\section{Participant Selection}

To reduce the bias of age and gender, a heterogeneous group of participants was selected. Forty people participated in the experiment and each session included two women and two men, from three age groups: 20-30, 31-50 and more than 50 years old. The ethical code in Brazil requires that participation in research experiments be voluntary, so the sessions were arranged based on participants' availability.

\section{Data analysis}

The collected personal information (InfoQ) and assessment questionnaires (FanQ) were processed in tables and matrices to analyze the results. Also, statistical analysis was performed to verify whether final preferences were dependent on fan assessment selection order or the experiment room operation mode variation. The same analysis was applied to verify if a significant relation could be established when comparing device selection with participants' anthropometric characteristics (weight, height and gender). To do so, Fisher's Exact Test was conducted considering a confidence level of $95 \%(p<0.05)$. This statistical test is the most appropriate for small sample sizes $(n=40)$ and categorical data analysis. The participant's weight and height collected in InfoQ were used to calculate body mass index (BMI) according to the nutrition ranges of the World Health Organization (WHO, no date). The measured environmental variables were also tabulated to analyze air temperature and relative humidity variation in each session.

\section{RESULTS}

\section{Participants' anthropometrics}

The participant selection was successful in building a heterogeneous group. As shown in Figure 2, 19 out of 40 participants were women (W) and 21 were men (M). The number of younger people (20 to 30 years old) was a little higher (42\%) than other age groups - 30\% were $31-50$ and $28 \%$ were more than 50 years old. Regarding body mass index (BMI), most of the participants (62\%) are considered to have a normal nutrition rate (WHO, no date). However, $28 \%$ fit into the pre-obesity category and the other $10 \%$ into obesity. Thus, the sample does not include underweight people and BMI groups are not similar in the set.

\section{Environmental variables}

The average indoor air temperature $\left(\mathrm{T}_{\text {air }}\right)$ among all experiment sessions was $28{ }^{\circ} \mathrm{C}$, reaching a maximum of $29.3^{\circ} \mathrm{C}$ in one session and a minimum of $26.9^{\circ} \mathrm{C}$ in another, while average relative humidity (RH) was $70 \%$ ranging from $57 \%$ to $82 \%$. Room thermal conditions varied throughout the experiment similarly in all sessions. Figure 3 illustrates this variation in the second session of the experiment, showing the gradual drop in air temperature $\left(T_{\text {air }}\right)$ after cooling activation and variation according to occupancy. When occupants left the room, air temperature and relative humidity tended to drop due to the decrease of humidity produced by breathing and transpiration and the reduction of heat exchange between participants and room air. While the air temperature kept decreasing, the relative humidity $(\mathrm{RH})$ increased again quickly when occupants returned to the room. The average variation of $\mathrm{T}_{\text {air }}$ was $1.5^{\circ} \mathrm{C}$ and $\mathrm{RH}$ was $15 \%$.

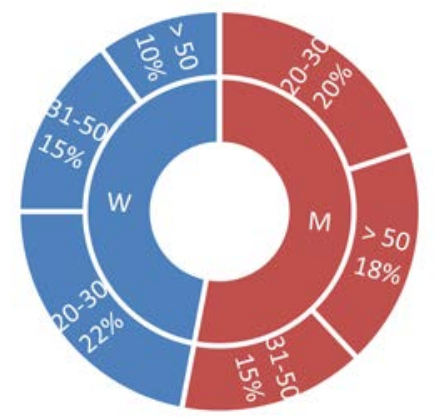

Figure 2. The proportion of participants per gender (Women in blue and Men in red) and age groups in years. 
The highest air temperature variation verified during the same session was $2.1{ }^{\circ} \mathrm{C}$ while $\mathrm{RH}$ reached $19 \%$ variation. Air temperature and relative humidity registered in the lab hallway and the building corridor, to which participants were exposed during breaks, were always lower than in the experiment room. On average, the hall was $1.5{ }^{\circ} \mathrm{C}$ and $5 \%$ below the experiment room; and the corridor, $4.7^{\circ} \mathrm{C}$ and $9 \%$ below the experiment room. Thus, when people left the experiment room during breaks (walks and coffee breaks) they likely felt this difference and a cooling sensation that may have affected their perception of experimental conditions. It has been observed in studies on transient spaces that this change between spaces with different temperatures can generate a sense of relief (Yu et al., 2016). And in this case, returning to the experiment room would generate the opposite effect, intensifying thermal discomfort by heat.

\section{Willingness to use a personal fan}

In the first questionnaire applied (InfoQ), participants were asked if they have a fan, and most of them (78\%) indicated they have it mainly at home; and $55 \%$ have a fan in their workspace. This could indicate that most would have a pre-disposition to use and may already like to use fans. However, the type of fan was not specified, so they could be used to either ceiling or

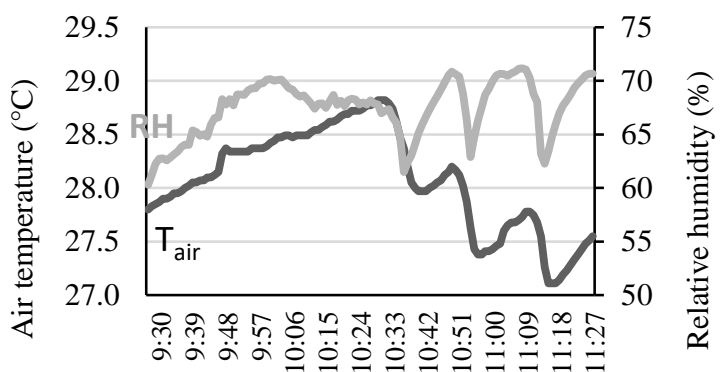

Figure 3. Air temperature ( $\left.\mathrm{T}_{\text {air }}\right)$ and relative humidity $(\mathrm{RH})$ registered during the second experiment session. standalone fans instead of small personal devices. As shown in Figure 4A, when initially asked (InfoQ) which operation mode they would usually use in a day with similar conditions to the experiment day, half of the participants indicated natural ventilation (NV) and the other half indicated air conditioning (AC). But fans would only be used with $\mathrm{NV}$ (NV+fan). However, Figure 4B, shows that 2 of those participants who use $\mathrm{AC}$ (5\% of total) and 1 of those who use NV+fan (2\% of total) preferred to use $\mathrm{NV}$ alone. By the end of the experiment, as shown in Figure 4C, some participants changed their opinion and most of them (62\%) indicated they would prefer either to use a fan associated with natural ventilation $(\mathrm{NV}+\mathrm{fan})$ or air conditioning $(\mathrm{AC}+\mathrm{fan})$ in a day like an experiment day. The preference ratio between overall $\mathrm{AC}$ and $\mathrm{NV}$ did not change significantly from $4 \mathrm{~B}$ to $4 \mathrm{C}$. However, almost half of those who prefer AC seemed to like the idea of using it with a personal fan and most of those who prefer NV thought it would be better to associate it with a personal fan. In the last questionnaire (FanQ), $72 \%$ of participants indicated they would like to have a personal fan in their workplace.

This result indicates that participants probably had no experience using a personal fan in a conditioned room before the experiment and being exposed to the test settings made them consider this possibility. Perhaps, turning on the fan while the air conditioning is on is counterintuitive. However, fans were accepted by part of participants as a thermal offset in a simulated situation, so the setpoint could be automatically extended to save energy. The impact on those who prefer natural ventilation was also noticeable. This result might indicate that a possible barrier to spread personal fans is the lack of experiences and opportunities to use them, as they are not usual in office buildings (Liu et al., 2018).
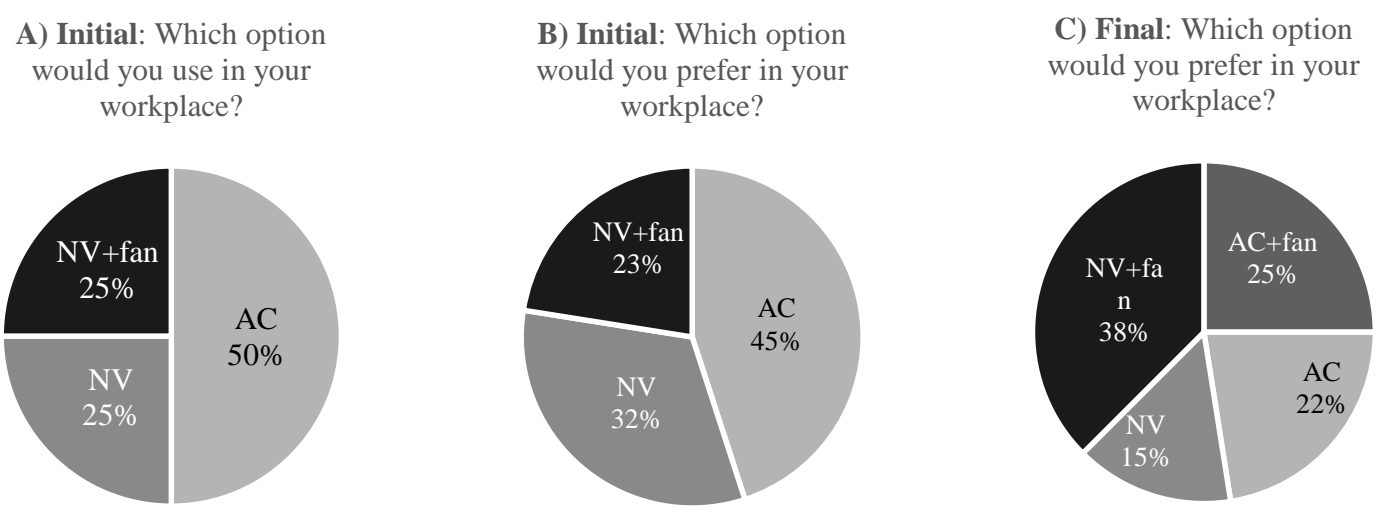

Figure 4. Preferred operation mode: natural ventilation (NV), natural ventilation with fan (NV+fan), air conditioning (AC), air conditioning with fan $(\mathrm{AC}+\mathrm{fan})$. 


\section{Assessment of fans aspects}

Participants were asked to indicate how important they would consider each of a set of criteria when buying a personal fan. Results are shown in Figure 5, in which the assessed criteria were grouped based on related aspects. Participants rated the most important criteria related to thermal and acoustic aspects. The most important criterion for most participants (73\%) was airflow sensation, followed by speed adjustment capability, considered the main aspect by $68 \%$. The only acoustic criterion in this rank - noise produced by the fan - was considered the most important by $63 \%$ of people. While the third thermal criterion - vertical rotation adjustment capability - was rated as the most important by only $48 \%$ of participants. And the last thermal criterion, the possibility of reaching higher airspeeds (higher maximum speed) was evaluated as the most important by a small number of people (18\%), and it seems to be either the second or fourth most important criterion for many participants. This means, adjusting and controlling airspeed is important, but not necessarily by increasing it. Financial aspects such as fan energy consumption and cost were also rated as the most important criteria for $40 \%$ of people each, and the second most important by most of them, especially the cost issue. The next most important criteria were the functional and practical ones, such as size and USB charge connection availability. By last, aesthetic aspects were rated as the least important, and the possibility to choose the device colour (18\%) seemed more important than general aesthetical issues (8\%).

It was expected that criteria related to controllability, like rotation and speed adjustment, would be highly rated by participants as control is one of the main functions of a personal conditioning device. However, results show people want to be able to control airspeed and direction, but the device must produce a pleasant sensation without noise and must be affordable as well. Achieving a higher airspeed seems, on the other hand, to be secondary to the participants.

\section{Device selection}

The last outcome of this experiment was to know which device participants would prefer, but before doing that the results were statistically analysed. Fisher's statistical analysis indicated that the selection of devices was not significantly influenced by the order in which they were evaluated. The same occurred with the operation mode of the air conditioner, the variation of operation mode did not significantly influence the selection of the fans by participants. Thus, it can be concluded that setting a random order of fan evaluation helped reduce the interference of other variables and the bias of device selection. This prevents, for example, that everyone preferred the first fan evaluated or the one that was in operation when the air conditioner was turned off. The FanQ questionnaire asked for an initial overall preference, and after asking which device they would consider the best regarding some specific aspect, the overall preference was asked again, but at this time considering a purchase situation, first disregarding the cost, and then considering the cost information presented. As can be noted by the results shown in Figure6A, the evaporative device - d - was evaluated as the best in most aspects by most participants. Only in the criterion related to the produced noise, device $\mathrm{b}$ was considered the best for most of the participants (48\%). Option c was pointed out as the quietest for only two people (5\%) even though options b and $\mathrm{c}$ show similar sound power measured levels (42 and $44 \mathrm{dBA}$ ), as indicated in Table 1. Option d stands out mainly on the aesthetic criterion, in which $68 \%$ of people found it the best option, while only one person pointed out option c as the best in this matter. Option c was chosen by more people than b mainly regarding the evaluation of which device provides the better thermal adjustment. The difference between $\mathrm{b}$ and $\mathrm{c}$ in this matter (8\%) was expected to be even greater, considering option b has only one airspeed level while option c has two, and both allow vertical rotation. Option d also stands out in this aspect, by having 23 airspeed levels (dial-like button), but no vertical adjustment capability.

Figure 6A shows the aspects ranking considering the importance of criteria analysed in section 3.4, where the most important is to provide a better sensation and the least important is aesthetics.

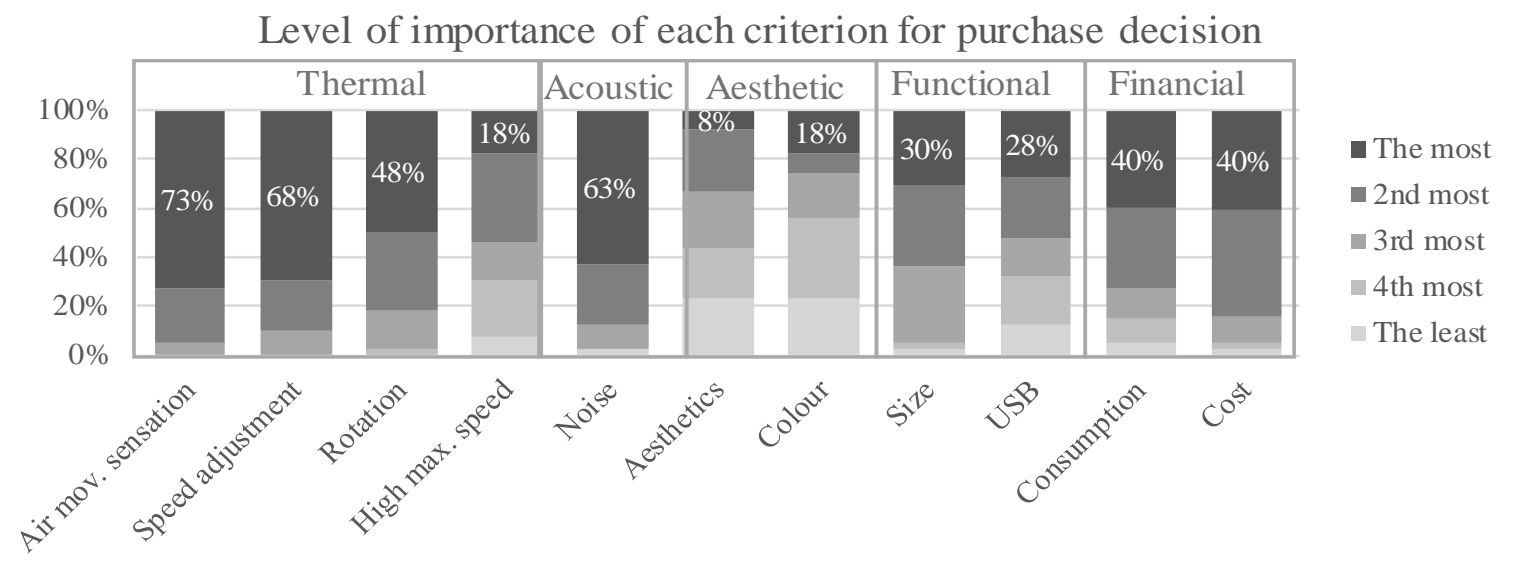

Figure 5. Importance of each criterion for purchase decision - FanQ. 
Hence, the results of purchase preference disregarding the cost shown in Figure $6 \mathrm{~B}$ is very consistent with the device ranking by aspect and the weight of aspects. By comparing initial and final preferences in Figure 6B disregarding cost, slight changes are observed. The evaluation per aspect seems to have influenced participants' perception and the main impact is the increase in votes to option $b$ and the decrease in votes to option c. Option d prevails as the preferred option in both initial and final questions disregarding the cost. However, when the cost was revealed - which is 40 times greater than the cost of option b, the cheapest device -, only one person indicated to be willing to purchase the evaporative device. As option b is cheaper than option c, the difference between them, which was $12 \%$ in the nocost question, rises to $18 \%$, and option $\mathrm{b}$ is positioned as the preferred option by most participants. This result shows that as the difference in costs becomes greater, this aspect becomes an eliminatory criterion. It is noteworthy that option a was not indicated as the best or preferred option in any question by any participant. On the other hand, the initial preference indicated that one person did not prefer any option and, after the evaluation by aspect, this number grew to two people. In other words, two people would not buy any of these fans, considering the options unsatisfactory.

By analysing the final choice of participants disregarding cost in face of their anthropometric characteristics, there was not enough evidence of a statistically significant association between purchase preference and categories of age, gender and BMI. Despite that, the evaporative device - $\mathrm{d}$ - was preferred mainly by people with normal BMI, women and people aged 31 to 40 years or over 50 years old in this experiment (see Figure 7). Regarding options b and c, it is noted in Figure 7 that men were equally divided in preference while women showed a higher preference for option b. Regarding BMI, option b stands out for people of a nutritional level considered normal (WHO, no date). And more people over 50 years preferred option c while the youngest - between 20 and 30 years - indicated a preference for option b. In a way, as the distribution of age groups and BMI among participants is not equitable, it could be considered that the sample generated a trend that favours option b over option c. In this way, both options could be considered satisfactory and with good cost-benefit by participants. On the other hand, if option d had a more affordable price, it would probably be the preferred option for most people and could achieve a better overall evaluation if it produced less noise.

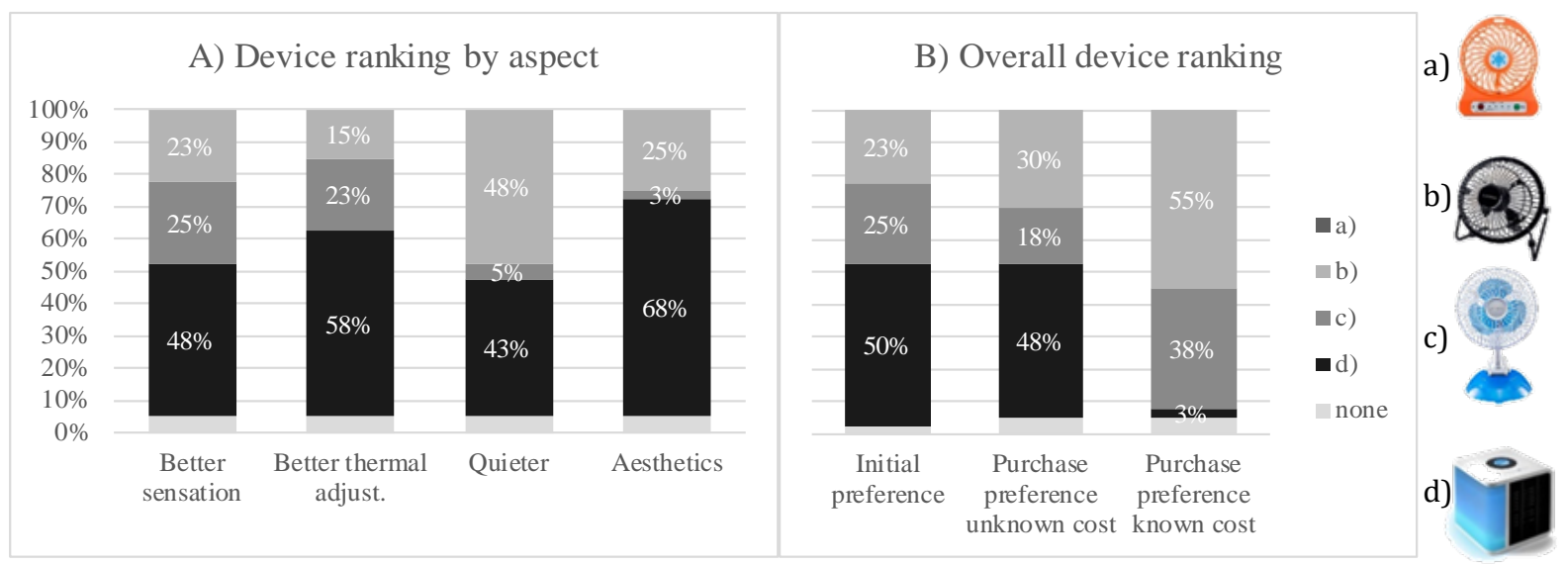

Figure 6. Device ranking by aspect and overall preference - FanQ.

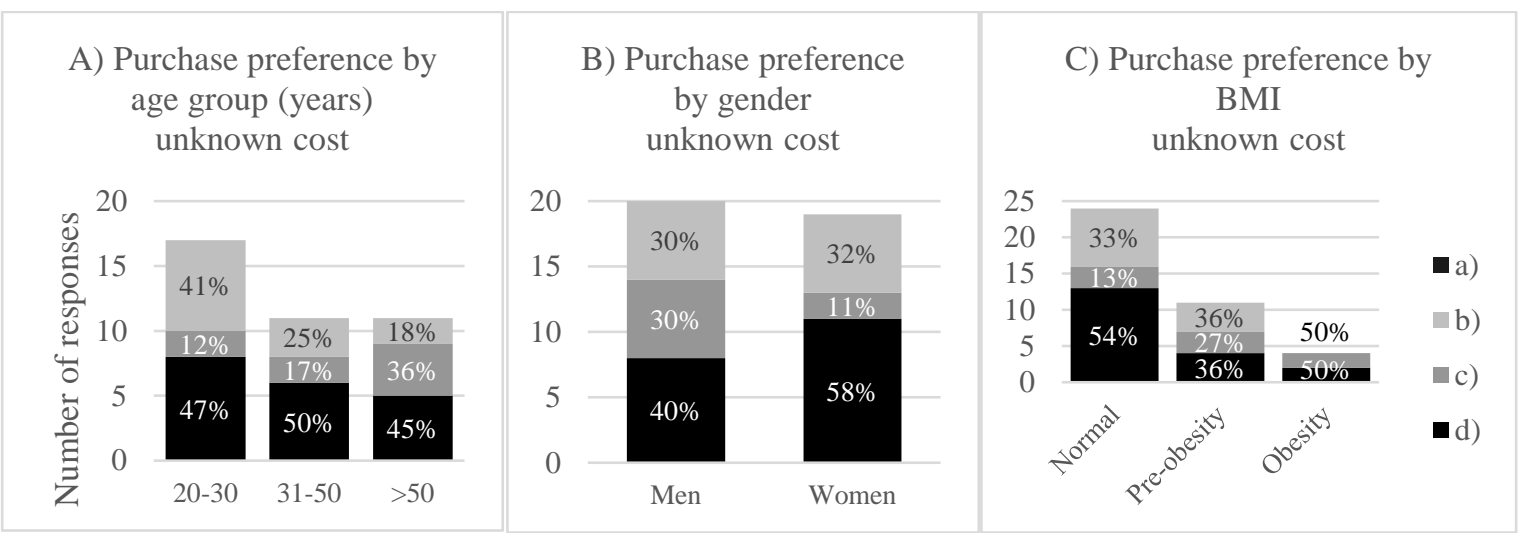

Figure 7. Device purchase preference disregarding cost by participants' anthropometric characteristic. 


\section{CONCLUSION}

The results presented in this paper allowed us to assess users' preferences regarding personal ventilative devices in a warm controlled working condition. The study highlights which aspects are considered most important for usability and device selection. As expected for a personal conditioning device, criteria related to controllability, like rotation and speed adjustment, were highly rated in importance by participants (the most important by $48 \%$ and $68 \%$ of participants, respectively). However, the noise produced by the fan was indicated as the third most important aspect (the most important by 63\%). However, two devices with similar measured sound power levels - b with $42 \mathrm{dBA}$ and c with $44 \mathrm{dBA}$ may be perceived differently, affecting their assessment regarding noise performance. Option b was considered the quieter by $48 \%$ of people while option c was rated as the quieter by $5 \%$. As the human sensory system receives information regarding multiple indoor environmental exposures simultaneously, sound effects should not be neglected when designing a personal device. Contextual factors such as affordability were also pointed out as an important criterion (the most important by $40 \%$ of participants), which was confirmed by the change in the trend of selected devices when purchase cost was revealed. Most participants preferred option d (48\%) but only one (3\%) was willing to pay for it. Interestingly, the possibility of increasing airspeed was not deemed as one of the most important like other thermal-related criteria. It was considered the most important criterion by only $18 \%$ and the second most important by $33 \%$ of the subjects. The most important criterion for most people (73\%) is the air movement sensation. Therefore, a smooth airflow with good controllability - such as the airflow produced by the evaporative device labelled as $\mathrm{d}$ - would be an optimal choice for office occupants in Brazilian offices in case this device becomes more affordable and quieter. Option d was considered by $48 \%$ to produce the better sensation and by $58 \%$ to allow better adjustment, which are the most important criteria for most participants. Moreover, the conducted experiment may have enlightened participants with the possibility of using both air conditioning and portable fans to achieve thermal comfort in their workspace during warm weather conditions. The cost was considered the second most important criterion for most participants (45\%) and had a great impact on a final choice. So, apart from improving design aspects, innovative solutions should be affordable to become popular. Also, if office occupants are stimulated to experience the use of desk fans and evaporative cooling devices with air conditioning, this operation mode might become usual.

The results discussed in this paper can help researchers to choose better equipment for their studies and help designers and companies to identify ways to improve the characteristics of desk fans. From the perspective of implementation, the use of desk fans in shared office spaces usually occurs in two ways, one in which the occupants purchase their equipment and another in which they receive the fan from someone like their employer. The initial omission of cost in the FanQ questionnaire intended to identify which aspects caught the participants' attention more regarding usability. Therefore, the results could guide both employers and employees to select a better device by knowing which aspects would be compared to achieve a good usability performance. Cost is a high impact factor, but cost-benefit will be different for an employer and an employee considering that employees do not have to deal with office space's energy cost. From the users' standpoint, the most expensive device (d) was the best for most people, but it was not costbeneficial. They would rather buy a cheaper fan, so the difference among fans regarding usability was evaluated as lower than cost differences. However, the cost-benefit calculation for the employer is more complex as it should consider employee satisfaction, productivity, the purchase cost of multiple devices and the possible energy savings achieved by the extension of setpoint temperature. From this standpoint, if the most expensive device would significantly increase users' satisfaction and their willingness to accept higher setpoint temperatures, it could be a costeffective option. However, further analyses would be needed to evaluate this long-term thermal comfort and energy-saving potential.

Participants' thermal perception responses during the experiment were collected, so a future publication will present the results regarding whether the thermal acceptability was the same using each fan. The impact of environmental conditions on device activation, airspeed and position adjustment will also be addressed. Another important issue that should be further investigated is the energy savings potential of using desk fans and extending setpoint temperature in the Brazilian context. This analysis will be carried out by computer simulation considering different setpoint temperatures and locations.

\section{CONFLICT OF INTEREST}

The authors declare that there are no conflicts of interest regarding this publication.

\section{ACKNOWLEDGMENT}

The work reported in this paper was supported by the Brazilian agencies Coordination for the Development of Higher Education Personnel - Brazil (CAPES), funding code number 001 - and the National Council for Scientific and Technological Development (CNPq). 


\section{REFERENCES}

André, M., De Vecchi, R. and Lamberts, R. (2020a) 'Feasibility of using personal fans for increasing thermal comfort in mixed-mode shared workspaces in Brazil: a field study, in NCEUB (ed.) Windsor Conference: resilient comfort in a heating world. London, UK: NCEUB (Network for Comfort and Energy Use in Buildings), p. 10.

André, M., De Vecchi, R. and Lamberts, R. (2020b) 'User-centered environmental control: a review of current findings on personal conditioning systems and personal comfort models', Energy and Buildings, 222. doi: 10.1016/j.enbuild.2020.110011.

ASHRAE (2020) 'Standard 169-2020 - Climatic Data for Building Design Standards’, p. 258.

Boerstra, A. (2010) 'Personal control in future thermal comfort standards?', in Network for Comfort and Energy Use in Buildings (ed.) Adapting To Change: New Thinking on Comfort. Windsor, Inglaterra.: Network for Comfort and Energy Use in Buildings, pp. 9-11.

Brager, G., Zhang, H. and Arens, E. (2015) 'Evolving opportunities for providing thermal comfort, Building Research and Information, 43(3), pp. 114. doi: 10.1080/09613218.2015.993536.

De Dear, R. (2011) 'Revisiting an old hypothesis of human thermal perception: alliesthesia', Building Research and Information, 39(2), pp. 108-117. doi: 10.1080/09613218.2011.552269.

He, M. et al. (2017) 'The influence of personally controlled desk fan on comfort and energy consumption in hot and humid environments', Building and Environment, 123, pp. 378-389. doi: 10.1016/j.buildenv.2017.07.021.

He, Y. et al. (2017) 'Comfort, Energy Efficiency and Adoption of Personal Cooling Systems in Warm Environments: A Field Experimental Study', International Journal of Environmental Research and Public Health, 14(11), p. 1408. doi: 10.3390/ijerph14111408.

Hoyt, T., Arens, E. and Zhang, H. (2015) 'Extending air temperature setpoints: Simulated energy savings and design considerations for new and retro fi t buildings', Building and Environment, 88, pp. 89-96. doi: 10.1016/j.buildenv.2014.09.010.

Knecht, K., Bryan-Kinns, N. and Shoop, K. (2016) 'Usability and design of personal wearable and portable devices for thermal comfort in shared work environments', in Proceedings of the 30th International BCS Human Computer Interaction Conference, HCI 2016, pp. 1-12. doi: 10.14236/ewic/HCI2016.41.

Liu, S. et al. (2018) 'Coordinate control of air movement for optimal thermal comfort Coordinate control of air movement for optimal thermal comfort', 4731.

doi: 10.1080/23744731.2018.1452508.

Luo, M. et al. (2018) 'Thermal comfort evaluated for combinations of energy-e ffi cient personal heating and cooling devices', Building and Environment, 143(April), pp. 206-216. doi: 10.1016/j.buildenv.2018.07.008.

Mishra, A. K., Loomans, M. G. L. C. and Hensen, J. L. M. (2016) 'Thermal comfort of heterogeneous and dynamic indoor conditions - An overview', Building and Environment, 109, pp. 82-100. doi: 10.1016/j.buildenv.2016.09.016.

Parkinson, T. and De Dear, R. (2016) 'Thermal pleasure in built environments: spatial alliesthesia from air movement'. doi: 10.1080/09613218.2016.1140932.

Peel, M. C., Finlayson, B. L. and McMahon, T. A. (2007) 'Updated world map of the Köppen-Geiger climate classification', Hydrology and Earth System Sciences, 11(5), pp. 1633-1644. doi: 10.5194/hess-11-1633-2007.

Schiavon, S. et al. (2017) 'Thermal comfort, perceived air quality, and cognitive performance when personally controlled air movement is used by tropically acclimatized persons', Indoor Air, 27(3), pp. 690-702. doi: 10.1111/ina.12352.

Schiavon, S. and Melikov, A. K. (2009) 'Introduction of a cooling-fan efficiency index', HVAC and $R$ Research, 15(6), pp. 1121-1144. doi: 10.1080/10789669.2009.10390882.

Schweiker, M. et al. (2020) 'Review of multi-domain approaches to indoor environmental perception and behaviour', Building and Environment, 176(December 2019), p. 106804. doi: 10.1016/j.buildenv.2020.106804.

Simone, A. et al. (2014) 'Thermal comfort assessment of danish occupants exposed to warm environments and preferred local air movement', Indoor Air 2014 - 13th International Conference on Indoor Air Quality and Climate, pp. 411-418. Available at: https://www.scopus.com/inward/record.uri?eid=2s2.0-

84924678156\&partnerID $=40 \&$ md5 $=\mathrm{c} 267 \mathrm{f} 839 \mathrm{f02c}$ 4ad091d122f8723cacf0.

Warthmann, A. et al. (2018) 'Personal climatization systems-a review on existing and upcoming concepts', Applied Sciences (Switzerland), 9(1). doi: 10.3390/app9010035.

WHO, W. H. O. (no date) Body mass index - BMI. Available at: http://www.euro.who.int/en/healthtopics/disease-prevention/nutrition/a-healthylifestyle/body-mass-index-bmi (Accessed: 24 January 2019).

$\mathrm{Xu}, \mathrm{Z}$. et al. (2017) 'Optimal coordination of air conditioning system and personal fans for building energy efficiency improvement', Energy and Buildings, 141, pp. 308-320. doi: 10.1016/j.enbuild.2017.02.051.

$\mathrm{Yu}, \mathrm{Z}$. (Jerry) et al. (2016) 'Utility of cooling overshoot for energy efficient thermal comfort in temporarily occupied space', Building and Environment, 109, pp. 199-207. doi: 10.1016/j.buildenv.2016.09.020.

Zhai, Y. et al. (2013) 'Comfort under personally 
controlled air movement in warm and humid environments', Building and Environment, 65, pp. 109-117. doi: 10.1016/j.buildenv.2013.03.022.

Zhai, Y. et al. (2017) 'Selecting air speeds for cooling at sedentary and non-sedentary office activity levels', Building and Environment, 122, pp. 247257. doi: 10.1016/j.buildenv.2017.06.027.

Zhang, H. et al. (2010) 'Thermal sensation and comfort models for non-uniform and transient environments
: Part I: Local sensation of individual body parts', Building and Environment, 45(2), pp. 380-388. doi: 10.1016/j.buildenv.2009.06.018.

Zhang, H., Arens, E. and Zhai, Y. (2015) 'A review of the corrective power of personal comfort systems in non-neutral ambient environments', Building and Environment, 91, pp. 15-41. doi: 10.1016/j.buildenv.2015.03.013. 